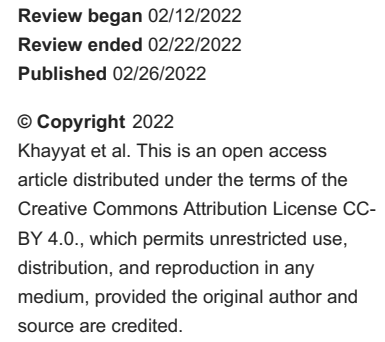

\section{Adherence to Hypoglycemic Agents in Type 2 Diabetes Mellitus: A Cross-Sectional Study}

\author{
Yara A. Khayyat Jr. ${ }^{1}$, Reem M. Alshamrani ${ }^{1}$, Doha M. Bintalib ${ }^{1}$, Najwa A. Alzahrani ${ }^{1}$, Sulafa Alqutub ${ }^{2}$ \\ 1. Family Medicine, Ministry of Health, Jeddah, SAU 2. Family and Community Medicine, University of Jedda, Jeddah, \\ SAU \\ Corresponding author: Yara A. Khayyat Jr., yara.khay@gmail.com
}

\begin{abstract}
Aims

This study aimed to elucidate the level and determinants of adherence to oral hypoglycemic agents (OHAs) among type 2 diabetes mellitus patients and to employ patient interview as a prediction tool for suboptimal adherence, for preventing and reducing complications.
\end{abstract}

\section{Methods}

In this analytical, cross-sectional study, 383 patients with type 2 diabetes mellitus were interviewed using an electronic, self-constructed, validated questionnaire. Patients were recruited from all Ministry of Health centers across Jeddah, through stratified random sampling. Univariate and multivariate logistic regression analyses were used to evaluate the significance of the results.

\section{Results}

Suboptimal levels of adherence were reported by $74.9 \%$ of the participants. Predictors of suboptimal adherence are as follows: younger age $(\mathrm{P}=0.003)$, employment [odd ratio $(\mathrm{OR}), 1.7 ; 95 \%$ confidence interval (CI), 1.1-3.0], unavailability of reminder (OR, 1.9; 95\% CI, 1.1-3.1), and non-commitment to appointments (OR, 6.1; 95\% CI, 1.1-3.1).

\section{Conclusion}

The level of adherence to OHAs was found to be suboptimal. Encountering any of the predictors of suboptimal adherence while interviewing the patient should prompt extra vigilance in the approach. Furthermore, utilizing methods to augment adherence might be prudent.

Categories: Endocrinology/Diabetes/Metabolism, Family/General Practice, Internal Medicine Keywords: medication, determinants, adherence, oral hypoglycemic agent, type 2 diabetes

\section{Introduction}

Diabetes mellitus (DM) is recognized as a genuine threat to public health [1]. By definition, diabetes is "a chronic, metabolic disease characterized by elevated level of blood glucose (or blood sugar), which leads over time to serious damage to heart, blood vessels, eyes, kidneys and nerves" [2]. This damage is often represented by complications, such as coronary artery disease, peripheral artery disease, stroke, blindness, renal impairment, and nerve damage [3]. The prevalence of diabetes among adults in Saudi Arabia is experiencing a rapid rise, it is expected that the total number of cases will reach around 7.5 million by 2035 [4]. Worldwide, diabetes mortality reached five million deaths, which outweighed the combined mortality of HIV/AIDS, tuberculosis, and malaria [5]. In fact, DM has been determined as the sixth leading cause of death in Saudi Arabia [6].

Adherence is indispensable for the successful management of DM [7]. If a patient does not implement the agreed-upon therapeutic plan, the treatment is rendered obsolete. Securing adherence is equivalent to securing the first step on a path leading away from complications [8].

According to the World Health Organization (WHO), the average rate of medication adherence is only $50 \%$ in developed countries. As for developing countries, it is estimated to be even lower [9].

In Saudi Arabia, the levels of adherence to oral hypoglycemic agents (OHA) differ from one region to another. Nevertheless, a suboptimal level of adherence prevails [10-13].

This growing healthcare issue is costly in multiple aspects. Its financial burden may surpass that of managing the disease itself [14]. In Saudi Arabia, the medical health expenditures of people with diabetes are 10 -fold higher than that of people without diabetes, which exerts an economic burden [15]. Furthermore, as 
suboptimal adherence may manifest as complications, it is the underlying cause of more than $30 \%$ of medicine-related hospital admissions [16]. Given the above, it is deleterious in terms of both health and economy [17].

Adherence and compliance are terms that are sometimes equated with one another and used interchangeably [18]. However, adherence is deemed superior to compliance, as it entails that the patient's management plan was mutually tailored by the healthcare provider and the patient [19]. WHO defines adherence as "the extent to which a person's behavior - taking medication, following a diet, and/or executing lifestyle changes - corresponds with agreed recommendations from a healthcare provider" [9]. Meanwhile, compliance is defined as "the extent to which the patient's behavior matches the prescriber's recommendations" [20]. Therefore, in this study, the term “adherence” will be mainly used.

Literature review shows a vast array of significant determinants of adherence [21]. These can be categorized into three major categories: the medical status [11], personal characteristics of the particular patient [22], and the agreed-upon therapeutic plan and medical encounter [9]. The personal characteristics contain the demographic data [22], forgetfulness [23], and personal beliefs [24]. The number of medications, complexity of the regimen, side effects, cost, and lack of trust in treatment efficacy are under the umbrella of the therapeutic plan and medical encounter [25].

The level of adherence among type 2 DM patients in Jeddah has been previously reported in a study [9]. However, there are some core differences between this study and the previous one: the earlier study was limited to the population of the national guard for health affairs and their three primary healthcare centers (PHCCs), whereas this study included PHCCs from all the clusters of the hospitals in Jeddah affiliated with the Ministry of Health, providing a better representative sample of the population of Jeddah. This is, to the best of the researchers' knowledge, unprecedented. In addition, this study used a scale, rather than a yes/no question, to measure adherence [9]. This study also identified the determinants of suboptimal adherence, by correlating the variables with adherence using the multiple logistic regression model, ultimately placing them in a frame that allows their use as components of a prediction tool, for suboptimal adherence while interviewing patients.

\section{Materials And Methods Study area and setting}

This study was conducted in Jeddah, which is the second-largest city in Saudi Arabia (population, 3.4 million)[26]. The PHCCs in Jeddah conform to a geographical clustering system affiliating them to hospitals among five sectors: King Abdullah Medical Complex (11 centers), King Abdulaziz Hospital (six centers), East Jeddah Hospital (10 centers), King Fahad Hospital (13 centers), and Al-Thagher Hospital (six centers). Outpatient services pertaining to various medical needs across all ages and stages of life are provided at these centers. Services to patients with DM, hypertension, and asthma are provided by chronic disease clinics at these centers.

\section{Study population}

The study population included patients with type 2 DM who attended the Ministry of Health PHCCs in Jeddah.

\section{Inclusion criteria}

Eligible participants were consenting adults aged $\geqslant 18$ years whose pharmacological management of type 2 DM was solely with OHAs and not with insulin. Participants who provided verbal consent were recruited for this study.

\section{Exclusion criteria}

Non-Arabic speakers were not recruited, as the questionnaire was in Arabic.

\section{Sampling technique}

Stratified random sampling was applied to the abovementioned sectors. The sample is proportional, and the selection process took place as follows: the centers in each sector were assigned numerical values as illustrated in Table 1. These values were entered in Random.org, and simple randomization was employed for each sector separately, resulting in a total of eight centers marked in Table 1. 


\section{Cureus}

\begin{tabular}{|c|c|c|c|}
\hline \multicolumn{3}{|l|}{ Affiliated centers* } & Hospital \\
\hline Al Riyadh & 2-Al Shaati & 1- Thwal & \multirow{4}{*}{ King Abdullah Medical Complex } \\
\hline Obhur AI Shamalyiah & 4- Al Wafa' & 3- Dhahban** & \\
\hline \multirow[t]{2}{*}{ 6- Alshiraa (505) } & Al Rayyan & 5- Al Hamdania & \\
\hline & 8- Specialized clinics & 7- Khalid Al Namothaji** & \\
\hline \multirow{3}{*}{ Ghulail } & 2-Al Qurayyat & 1- Mada'in Al Fahad & \multirow{3}{*}{ King Abdulaziz Hospital } \\
\hline & 4- Al Thaaliba & 3-Al Balad & \\
\hline & 6- Al Qarinia & 5- Al Mahjar** & \\
\hline Al-Sulaimanyah & 2-Al Jamieah & 1-Briman & \multirow{4}{*}{ East Jeddah Hospital } \\
\hline 5- Al Rabie and Al Tawfiq ${ }^{* *}$ & 4- Al Rawabi & 3- Raghamah & \\
\hline 7- Al Matar Al qadim & 6- Al-Rehab & Guaizah & \\
\hline \multicolumn{3}{|l|}{ 8- Shraq Al Khati Al sarie ${ }^{\star *}$} & \\
\hline 3- Al Azizia & 2- Al Nahda & 1- Al Ruwais & \multirow{5}{*}{ King Fahad Hospital } \\
\hline 5- Al Salamah & 4- Al Naeim & Al Hamraa & \\
\hline 8- Al-Safa (2) & 7- Al Rabwa & 6- Al Marwa & \\
\hline 11- Al-Bawadi & 10- Al-Faisaliah** & 9- Al-Safa $(1)^{\star *}$ & \\
\hline \multicolumn{3}{|l|}{ 12- Mushrifa } & \\
\hline 3-Al Harazat & 2- Kilo $14^{* *}$ & 1-Prince Abdul-Majeed & \multirow{2}{*}{ Al-Thagher Hospital } \\
\hline Kilo 13 & 5- Om Al Silm & 4- Al Muntazahat & \\
\hline
\end{tabular}

\section{TABLE 1: The Ministry of Health sectors and related primary healthcare centers in Jeddah}

* Due to the COVID-19 pandemic, some centers were assigned to serve only suspected coronavirus cases. Hence, they were not assigned a numerical value; they were eliminated from the randomization process. The Al Riyadh Center was also eliminated from randomization because it was closed.

** These are the eight primary healthcare centers selected by simple randomization.

\section{Data collection}

The instrument used was an electronic, self-constructed, validated questionnaire (Appendix 1: Figures 1-5). The questionnaire was in Arabic and contained three sections. The first section collected demographic data. The second section measured adherence using the Iraqi Antidiabetic Medication Adherence Scale (IADMAS) (Table 2). To the best of the researchers' knowledge, there is no specific tool to measure the level of adherence to DM medication in the Arab population. However, a pilot study in Iraq formulated the IADMAS, which was validated and proven to be reliable, with a sensitivity of $100 \%$ and specificity of $33.9 \%$. This scale has a statistically significant high correlation with the Medication Adherence Questionnaire of Morisky [27], which is the nearest to a gold standard for measuring medication adherence [28]. The last section of the questionnaire is a self-constructed section that assesses the determinants of adherence, which was developed based on a literature review. 


\section{Cureus}

Item

1. During the last month, how many times did you forget to take your medication(s)?**

2. During the last month, how often did you take your medications deliberately in a dose different than what was prescribed for you?

3. During the last month, how often did you take your medications deliberately at a different time than was prescribed for you?

Item

4. During the last month, did you take your medication(s) with you when leaving the house (as when visiting relatives or traveling)?

5. During the last month, did you stop taking your medication(s) without seeking medical consultation because of side effects?

6. During the last month, did you take lesser amounts of your medication(s) without seeking medical consultation because you felt better?

7. During sick days (as in influenza or diarrhea), do you take lesser amounts of your medication(s) without seeking medical consultation because of decreased appetite?

8. During the last month, did you take your medication(s) in lesser amounts because it was expensive?

\begin{tabular}{|c|c|c|c|c|}
\hline Always & Often & Sometimes & Rarely & Never \\
\hline 0 & 0.25 & 0.5 & 0.75 & 1 \\
\hline 0 & 0.25 & 0.5 & 0.75 & 1 \\
\hline 0 & 0.25 & 0.5 & 0.75 & 1 \\
\hline Yes & & No & & \\
\hline 1 & & 0 & & \\
\hline 0 & & 1 & & \\
\hline 0 & & 1 & & \\
\hline 0 & & 1 & & \\
\hline 0 & & 1 & & \\
\hline
\end{tabular}

\section{TABLE 2: Determining adherence level by using the IADMAS*}

*A total score of 8 is classified as high adherence level, $7.75-6$ is classified as medium adherence level, $5.75-0$ is classified as low adherence level.

${ }^{* *}$ This item targets unintentional non-adherence. All other items target intentional non-adherence.

IADMAS: Iraq Antidiabetic Medication Adherence Scale.

Data were collected between the end of November 2020 and the beginning of February 2021, throughout which the Corona pandemic occurred. With our targeted population being patients with type $2 \mathrm{DM}$, the interviews after the pilot study were resumed virtually through phone calls. Contact numbers were acquired from the chronic disease clinics, the daily visits records, and electronic databases, according to the infrastructure of the randomized center of interest.

\section{Study design}

This was an analytical, cross-sectional study.

\section{Sample size planning}

The sample size was calculated using the Raosoft website [29] with an accepted margin of error of 5\%, estimated population size of 20,000 , level of adherence of $64.3 \%$, and confidence level of $95 \%$. The calculated sample size was 347 patients. To compensate for defaulters and nonrespondents, $10 \%$ of the calculated sample size was added. Thus, the total sample size was 382 participants.

A pilot study using convenience sampling was conducted on $10 \%$ of the total sample, which is equivalent to 38 patients. These patients and centers were not included in the final sample.

\section{Data entry}

Data were entered through tablets, computers, and mobile devices into a SurveyMonkey database [30], from which it was exported in Excel format.

\section{Data analysis}

Responses containing missing data pertaining to the IADMAS or response errors were omitted. Hence, statistical analysis was carried out on 383 out of a total of 391 responses. The Statistical Package for the Social Sciences (SPSS ${ }^{\circledR}$ ) version 20 (IBM Corp., Armonk, NY) was used for statistical analysis. Categorical variables were described by frequency and percentage, whereas continuous variables were described by mean \pm SD. The total score of adherences was classified into two categories, optimal and suboptimal, according to the cutoff point. Chi-square test was employed to assess associations between adherence and categorical 


\section{Cureus}

data. Multiple logistic regression analysis was employed to determine the predictors of adherence that were proved to be significant in the univariate analysis. The accepted level of significance was set below 0.05 $(\mathrm{p}<0.05)$.

\section{Ethical consideration}

Ethical approval for conducting this study was obtained from the research committee of the Joint Program of Family Medicine, in Jeddah, and the Ministry of Health's Institutional Review Board (H-02-J-002), and the study was conducted in accordance with the principles of the Declaration of Helsinki. The confidentiality and anonymity of all participants were ensured. Verbal consent was obtained from each participant.

\section{Results}

\section{Sociodemographic and clinical characteristics of the participants}

The mean age of the participants was 57.1 years (standard deviation, 10.6 years). Their ages ranged from 20 to 92 years. Most participants were males (53.3\%), married (71.5\%), and working (71.3\%). About half (52.7\%) had school-level education, whereas $35 \%$ had university-level education. The majority were prescribed two or less OHAs per day (67.6\%). The frequency of medications was reported as twice per day by $35.3 \%$ and three times per day by $38.1 \%$ of participants. Having other chronic diseases was reported by $23.2 \%$ of the participants (Table 3). Regarding the total number of medications per day, $45.2 \%$ had more than five medications per day, and $38.6 \%$ had three to five medications per day.

Age (years)

$\leq 40$

$41-59$

Gender

Female

Marital status

Married

Working status

Yes

Working hours per week $(n=110)$

$\leq 40$

Level of education

School

University

Smoking

Yes

Duration since diagnosis with diabetes (years) 


\section{Cureus}

$\begin{array}{ll}6-16 & 158\end{array}$

Other chronic diseases

Yes

No

Type of chronic diseases

Hypertension

Epilepsy

Asthma

Anemia

Hyperthyroidism

Hypothyroidism

Complications

\section{Retinopathy}

Tingling extremities

Nephropathy

Other medications

No

Frequency of diabetes medications per day

Once

Twice

Three times

Total number of medications/day
$<3$
62

\section{TABLE 3: Sociodemographic and clinical characteristics of the participants}

CVA: Cerebrovascular accident

\section{Level of adherence}

High adherence was reported by $25.1 \%$ of the participants $(n=98)$, whereas medium and low adherence was reported by $56.1 \%(n=219)$ and $17.8 \%(n=68)$ of the participants, respectively. Suboptimal adherence was defined as medium or low adherence and was reported by $74.9 \%$ of the participants. A summary of the responses from which the level of adherence was determined is demonstrated in Table 4. 


\section{Cureus}

Item

1. During the last month, how many times did you forget to take your medication(s)?

2. During the last month, how often did you take your medications deliberately in a different dose than what was prescribed for you?

3. During the last month, how often did you take your medications deliberately at a different time than was prescribed for you?

Item

4. During the last month, did you take your medication(s) with you when leaving the house (as when visiting relatives or traveling)?

5. During the last month, did you stop taking your medication(s) without seeking medical consultation because of side effects?

6. During the last month, did you take lesser amount of your medication(s) without seeking medical consultation because you felt better?

7. During sick days (as in influenza or diarrhea), did you take lesser amount of your medication(s) without seeking medical consultation because of decreased appetite?

8. During the last month, did you take your medication(s) in lesser amounts because it was expensive?

\begin{tabular}{|c|c|c|c|c|}
\hline $\begin{array}{l}\text { Always } \\
\text { (1) }\end{array}$ & $\begin{array}{l}\text { Often } \\
\text { (2) }\end{array}$ & $\begin{array}{l}\text { Sometimes } \\
\text { (3) }\end{array}$ & $\begin{array}{l}\text { Rarely } \\
\text { (4) }\end{array}$ & $\begin{array}{l}\text { Never } \\
\text { (5) }\end{array}$ \\
\hline $\begin{array}{l}6 \\
(1.6 \%)\end{array}$ & $\begin{array}{l}16 \\
(4.2 \%)\end{array}$ & $36(9.4 \%)$ & $\begin{array}{l}101 \\
(26.4 \%)\end{array}$ & $\begin{array}{l}224 \\
(58.5 \%)\end{array}$ \\
\hline $\begin{array}{l}8 \\
(2.1 \%)\end{array}$ & $\begin{array}{l}10 \\
(2.6 \%)\end{array}$ & $16(4.2 \%)$ & $\begin{array}{l}28 \\
(7.3 \%)\end{array}$ & $\begin{array}{l}321 \\
(83.8 \%)\end{array}$ \\
\hline $\begin{array}{l}9 \\
(2.3 \%)\end{array}$ & $\begin{array}{l}21 \\
(5.5 \%)\end{array}$ & 52 (13.6\%) & $\begin{array}{l}77 \\
(20.1 \%)\end{array}$ & $\begin{array}{l}224 \\
(58.5)\end{array}$ \\
\hline Yes & & No & & \\
\hline \multicolumn{2}{|c|}{$293(76.5 \%)$} & 90 (23.5\%) & & \\
\hline \multicolumn{2}{|c|}{40 (10.4\%) } & $343(89.6 \%)$ & & \\
\hline \multicolumn{2}{|c|}{72 (18.8\%) } & $311(81.2 \%)$ & & \\
\hline \multicolumn{2}{|c|}{$69(18 \%)$} & $314(82 \%)$ & & \\
\hline \multicolumn{2}{|c|}{$22(5.7 \%)$} & $361(94.3 \%)$ & & \\
\hline
\end{tabular}

\section{TABLE 4: Summary of responses to the direct adherence questions using the IADMAS}

IADMAS: Iraqi Antidiabetic Medication Adherence Scale

Factors associated in univariate analysis with suboptimal adherence

In univariate analysis, suboptimal adherence was significantly higher among those who were working, compared with those who were not [odds ratio (OR), 1.7; 95\% confidence interval (CI), 1.1-3.0], those who did not have a reminder available (OR, 1.7; CI, 1.2-2.7), those who did not commit to refill of medications and/or follow-up appointments with a doctor (OR, 5.9; CI, 1.3-25.1), those who did not identify disbelief in the medication benefit as the reason for stopping their medications (OR, 2.1; CI, 1.1-4.1) (Table 5 and Table 6).

Adherence
Suboptimal n (\%) Optimal n (\%)

Age (years)

$\leq 40$

41-59

$\geq 60$

Gender

Female

Male

Marital status

Married

Not married

Working status

Yes
24 (85.7)

$140(77.8)$

$123(70.3)$

138 (77.1)

149 (73.0)

209 (76.3)

78 (71.6)

$90(81.8)$
OR

$95 \% \mathrm{Cl}$

P-value

4 (14.3)

40 (22.2)

$52(29.7)$

41 (22.9)

1.2

$0.8-1.98$

0.361

55 (27.0)

65 (23.7)

1.3

$0.8-2.10 \quad 0.336$

31 (28.4)

$20(18.2)$

1.7

$1.1-3.0 \quad 0.045$ 


\section{Cureus}

No

Working hours per week $(n=110)$

$\leq 40$

$>40$

Level of education

School

University

No

Smoking

Yes

No

Duration since diagnosis with diabetes (years)

$\leq 5$

$6-16$

$>16$

Other chronic diseases

Yes

No

Other medications

Yes

No

Frequency of diabetes medications per day

Once

Twice

Three times

Four times or more

Total number of medications/day

$<3$

$3-4$

$\geq 5$
197 (72.2)

53 (77.9)

37 (88.1)

145 (71.8)

108 (80.6)

34 (72.3)

61 (77.2)

226 (74.3)

130 (75.1)

$118(74.7)$

39 (75.0)

65 (73.0)

222 (75.5)

$24(27.0)$

72 (24.5)

43 (67.2)

244 (76.5)

21 (32.8)

0.6

75 (23.5)

42 (82.4)

$100(73.5)$

109 (74.7)

36 (72.0)

49 (79.0)

74 (74.7)

164 (73.9)

$15(22.1)$

0.5

5 (11.9)

$57(28.2) \quad 0.9$

26 (19.4)

1.6

$13(27.7)$

18 (22.8)

1.7

78 (25.7)

$43(24.9) \quad 1.0$

40 (25.3)

0.9

$13(25.0)$

$$
9 \text { (17.6) }
$$

1.8

$36(26.5)$

1.1

37 (25.3)

$14(28.0)$

1.1

$13(21.0)$

1.2

25 (25.3)

1.1
$0.2-1.4 \quad 0.180$

0.5-1.9 0.172

Reference

$0.7-3.4 \quad 0.239$

$0.7-2.1 \quad 0.600$

$0.5-2.1 \quad 0.983$

0.5-2.0 0.964

Reference

$0.5-1.5 \quad 0.643$

$0.4-1.1 \quad 0.117$

$0.7-4.7$

0.218

$0.5-2.2 \quad 0.835$

$0.6-2.3 \quad 0.712$

Reference

$0.7-2.6$

0.709

$0.6-1.8 \quad 0.871$

reference

TABLE 5: Association between suboptimal adherence and sociodemographic and clinical characteristics of the participants

OR: odds ratio; $\mathrm{Cl}$ : confidence interval.

\begin{tabular}{l|l|l|l|} 
Adherence & OR & $\mathbf{9 5 \%} \mathrm{Cl}$ & $\begin{array}{l}\text { P- } \\
\text { value }\end{array}$ \\
\hline $\begin{array}{l}\text { Suboptimal } n \\
(\%)\end{array}$ & $\begin{array}{l}\text { Optimal } n \\
(\%)\end{array}$ & \\
\hline
\end{tabular}

Available reminder 


\section{Cureus}

No

Yes

Commitment to refill appointments

No

Yes

Perceived commitment to medications refill and/or follow-up appointment

No

Yes

Family as a reported source of support

No

Yes

Friends as a reported source of support

No

Yes

Doctors as a reported source of support

No

Yes

Reported stopping because medications are not beneficial

No

Yes

Medical team explanation

No

Yes

Commitment to doctor appointment

No

Yes

Reported discussion of therapeutic plan with the medical team

No

Yes

Type of reminder

Incorporating into daily routine

Family member/care provider/alarm

Organizers
211 (77.9)

76 (67.9)

60 (22.1)

1.7

1.2-2.7 0.040

36 (32.1)

53 (77.9)

$15(22.1)$

1.2

$0.7-2.3 \quad 0.528$

234 (74.3)

81 (25.7)

$32(94.1)$

2 (5.9)

5.9

1.3-

25.1

0.007

255 (73.1)

94 (26.9)

$150(71.8)$

$59(28.2)$

0.7

$0.4-1.1 \quad 0.117$

137 (78.7)

37 (21.3)

275 (74.5)

94 (25.5)

0.5

$0.1-2.2 \quad 0.343$

12 (85.7)

2 (14.3)

235 (73.4)

85 (26.6)

0.6

$0.3-1.2 \quad 0.125$

$52(82.5)$

$11(17.5)$

262 (76.6)

80 (23.4)

2.1

$1.1-4.1 \quad 0.029$

25 (61.0)

16 (39.0)

105 (75.0)

35 (25.0)

1.1

$0.62-$

1.6

0.980

182 (74.9)

61 (25.1)

79 (79.8)

$20(20.2)$

1.4

$0.8-2.5 \quad 0.195$

208 (73.2)

76 (26.8)

74 (71.8)

$29(28.2)$

0.8

$0.4-1.3 \quad 0.397$

213 (76.1)

67 (23.9)

12 (57.1)

9 (42.9)

0.6

$0.3-1.9 \quad 0.567$

55 (67.1)

27 (32.9)

0.8

$0.2-2.3 \quad 0.088$

8 (88.8)

1 (11.2)

Reference

TABLE 6: Association between suboptimal adherence and support among the participants

OR: odds ratio; $\mathrm{Cl}$ : confidence interval.

Factors associated in multivariate analysis with suboptimal adherence 


\section{Cureus}

In multivariate analysis, factors that predicted suboptimal adherence were as follows: no reminder available (OR, 1.9; CI, 1.1-3.1), no perceived commitment to medication refill and/or follow-up appointments with a doctor (OR, 6.1; CI, 1.1-3.1), and did not report stopping medications because medications were not beneficial (OR, 2.0; CI, 1.05-4.1). Age was inversely related to suboptimal adherence; suboptimal adherence decreased as age increased ( $\mathrm{p}=0.003)$. The total model was significant, and there was no multicollinearity. The model fitted the data (Hosmer test p-value, 0.567) (Table 7).

\begin{tabular}{|c|c|c|c|}
\hline & B & Adjusted OR (95\% Cl) & P-value \\
\hline Age & -0.038 & $0.9(0.93-0.98)$ & 0.003 \\
\hline \multicolumn{4}{|c|}{ Available reminder } \\
\hline No & 0.625 & $1.9(1.1-3.1)$ & 0.017 \\
\hline Yes & \multicolumn{3}{|l|}{ Reference } \\
\hline \multicolumn{4}{|c|}{ Perceived commitment to medications refill and/or follow-up appointment } \\
\hline No & 1.810 & $6.1(1.4-26.5)$ & 0.016 \\
\hline Yes & Reference & & \\
\hline \multicolumn{4}{|c|}{ Reported stopping because of disbelief in medication benefit } \\
\hline No & 0.702 & $2.0(1.05-4.1)$ & 0.038 \\
\hline Yes & Reference & & \\
\hline
\end{tabular}

\section{TABLE 7: Factors associated with suboptimal adherence in multiple logistic regression analysis}

OR: odds ratio; Cl: confidence interval; B: regression coefficient.

\section{Discussion}

In its report on medication adherence, the WHO stated that "increasing the effectiveness of adherence interventions may have a far greater impact on the health of the population than any movement in specific medical treatment" [9]. Adherence is an ally of a better quality of life and overall health. Low adherence has been associated with inadequate glycemic control and increased rates of morbidity and mortality [9].

Studies from the eastern, central, and southern regions of Saudi Arabia have reported unanimous results of suboptimal adherence with the levels being $67.9 \%, 64.3 \%$, and $89.3 \%$, respectively [10-12]. In this study, the adherence level was no exception; the level of suboptimal adherence was $74.9 \%$. These data offer a compelling invitation to pursue the roots of this issue and explore it further.

Previous studies showed contrasting results with regards to whether there was an association of adherence to age and gender. This study found that adherence is inversely associated with age, the younger the age, the higher the percentage of suboptimal adherence. This is in good agreement with the findings of a study done in Abha city, Saudi Arabia [22], and other studies done outside Saudi Arabia [5,31].

As for gender, studies performed in Gaza and Al Hasa showed a statistically significant association between female gender and higher levels of adherence [10,32]. In this study and in a study performed in the central region of Saudi Arabia, males reported higher levels of adherence, compared with females [17]. The p-value for gender reflects no statistical significance in this study. However, in the aforementioned study from the central region, there was statistical significance, which renders the statistical significance peculiarly varied [17].

The results substantiate previous findings in the literature that have identified the patient's working status [25], beliefs about the consequences of diabetes medication [24], and having a reminder as being important determinants of adherence [33]. Most of the study participants relied on caregivers and alarms to remind them to take their medications.

As for the variable measuring the patient belief toward medications, in order to conform to the adherence definition, the question that was used to assess this variable further specified the behavior to be without the healthcare provider's consult. However, belief in the beneficence of the medication intertwines with the trust in the healthcare provider. If the patients do not trust the healthcare providers, they will not consult them before stopping the medication that is not beneficial according to the patients' belief, which leads to 
the therapeutic relationship being a potential confounder. Therefore, as accurate as this result might be for the specific question asked, it might not purely reflect the intended variable.

Forgetfulness [9], behavior-related factors (such as taking medications in different doses at different times), and side effects are well-documented influencers of adherence [34]. The study population reported that $41.5 \%$ forgot to take their medications at least once. Patients deliberately took their medications at different times and in different doses than was prescribed in $16.2 \%$ and $41.5 \%$ of cases, respectively.

The quality of the treatment relationship has been recognized as an important determinant of adherence [25]. An effective treatment relationship is characterized by an atmosphere in which alternative therapeutic means are explored, the regimen is negotiated, adherence is discussed, and follow-up is planned [9]. This is compatible with the results of the variable of general commitment to medications refill and/or follow-up appointments with doctors. The variable is significantly associated with a suboptimal level of adherence. In light of these results, it might be beneficial to introduce systems that alert clinicians to the irregularity or loss of follow-up, which keeps track of this indicator of potential suboptimal adherence. The results here delineated no statistically significant association between the discussion of the therapeutic plan and adherence, which could be related to cultural factors.

In this study, the effect of health literacy was measured in the form of explanation of type $2 \mathrm{DM}$ and its complications by the medical team to the patients. Even though this result differs from that of some earlier studies [34], no significant association was noted between medical education and adherence to medication in this study. It is plausible that the level of health literacy, in regards to DM in Jeddah, is exceptionally high. A comparison of the studies measuring the level of knowledge about DM conducted in Jeddah [23] and adjacent areas, such as Al Riyadh [35], Makkah [36], Kuwait [37], and Al Ismailia in Egypt [38], showed that patients in Jeddah had more knowledge about DM, which lends support to this hypothesis.

In this study, the IADMAS was used to measure adherence. This is a subjective measurement, which could be perceived as a limitation in the sense of susceptibility to recall bias. However, the IADMAS limited the recalling interval to only one month, which is expected to minimize the risk of recall bias.

Adherence could be affected by the cost of medications, which was not included among the variables in this study. The Ministry of Health's PHCCs provide free medications. Nevertheless, the cost is already very well documented as a determinant of adherence $[39,40]$.

\section{Conclusions}

The study found that the level of adherence is suboptimal among patients with type 2 DM in Jeddah. Suboptimal adherence to OHA results in an increase in mortality, morbidity, and financial burden. We recommend being extra vigilant when encountering an influencer or a predictor of suboptimal adherence while interviewing the patient. In addition, it might be prudent to utilize methods to further secure and augment adherence; thus, employing prevention to counteract possible suboptimal adherence.

\section{Appendices}




\section{Cureus}

1. العمر (بالسنوات )

2. الجنس

ذكر

أنثى

3. الحالة الاجتماعِية

متزوج/ة

أرمل/ة

منفصل/اة

اعزب/عزباء

4. حالة التذخين

مذن حالي

مدخن سابق

غير مذفن

مخالط لمنفنين

5. مستوى التعليم

ابتكاني

متوسط

ثنانوي

مبرة

كلية

جامعي

ماجستير

دكتبرة

Other (please specify)

6ل تصن؟

نعم

y

7. عدد ماعات العمل في الأسبوع:

ساعة الاعبوع

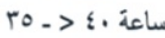

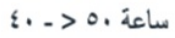

ساعة 00 > > > - 0.

ماعة 00 ماعة >0

FIGURE 1: (A) The questionnaire form in Arabic 


\section{Cureus}

8. ما هو معدل دخلك الشهري؟

$<0,$.

$0 \ldots->1 \ldots$

$1, \ldots+\cdots-r_{1}, \ldots$

$r_{1}, \ldots+r_{-1}>r_{0}, \ldots$

$>=r 0, \ldots$

9. حاول تذكر كيف قمت بتناول الأدوية الخاصة بالسكري ثم أجب عن الأسنلة التالية النالية

خلال الشهر الماضي، كم مرة نسيت أن تأخذ أدويتك ؟

[score 0]

[score 0.25]

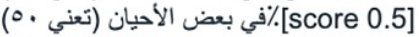

[نادزا (تعني (score 0.75]

[ أبدًا (تعني · ) [score 1]

خلال الشهر الماضي، كم مرة تعدت أخذ أدويتك بجر ع تختلف عما هو موصوف للك ؟ . 10.

[score 0]

[score 0.25]

[score 0.5]

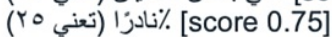

[ أبذًا (تعني · (score 1]

خلال الشهر الماضي، كم مرة تعددت أخذ أدويتك بوقت يختلف عما هو موصوف للك ؟ . 11.

[score 0]

[score 0.25]

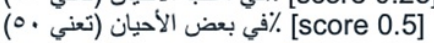

[score 0.75]

[ أبدًا (تعني · )

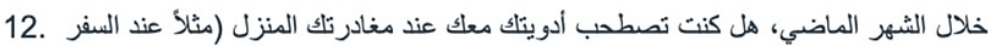

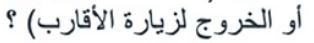

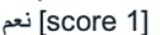

$\checkmark$ [score 0]

خلال الشهر الماضي، هل توققت عن استخدام أدويتك دون استشارة طبية بسبب الأعراض .13

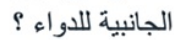

[score 0]

$\checkmark[$ score 1] 


\section{Cureus}

14. خلال الشهر الماضي، هل قمت بأخذ كمية أقل من أدويتك دون استشارة طبية بسبب شعورك

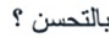

لع [s score 0]

$\mathrm{V}$ [score 1]

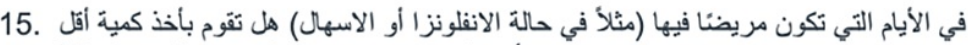

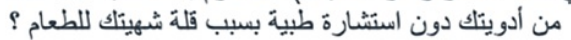

[score 0]

$\mathrm{y}$ [score 1]

خلال الثهر الماضي، هل قمت بأخذ كمية أقل من أدوينك بسبب غلانها ؟ .

[score 0]

$\mathrm{V}$ [score 1]

17. Level of adherence:

High adherence [score 8]

Medium adherence [score 7.75-6]

Low adherence [score 5.75-0]

18. منذ متى تم تشخيصك بمرض السكري ؟

يوم

شنهُ

19. منذ منى بدأت تناول أدوية السكري

يوم

شنهر

20. كم عدد أدوية السكري التي تنتاولها بشكل مستمر ؟

21. كم مرة في اليوم تنتاول أدوية السكري

22. هل تثناول أدوية غير أدوية السكري

لإ

23. إذا كانت الإجابة بنعم، كم عددها؟

FIGURE 3: (C) The questionnaire form in Arabic 


\section{Cureus}

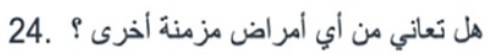

نام

25. إذا كانت الإجابة بنعم، ماهي الأمراض المزمنة التي تعاني منها ؟ ارنفاع ضغط الدام

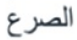

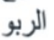

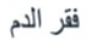

نشاط/فرط الغدة الدرقية الغية

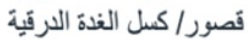

أخرى ( مثل أمراض القلب و الثرايين، العرطان...)

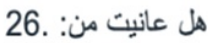

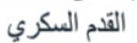

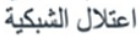

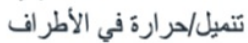

قصور / فثل كلوي الاطري

جلطة قلبيةً

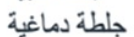

27. هل تثوفر لديك وميلة تذكير لتناول أدويتك؟

لا

28. إذا كان الجواب نعم، اذكرها؟

29. ممن تثلقى الدعم المعنوي بخصوص مرض السكري؟

عانلثt

أصدقانك

طبيبك

لا تشلى أي دعم

30. لمت تمناقشة و إيضاح خطناك العلاجية من قَبل الفريق الطبي قبل اعتمادها؟

لا

31. هل تم شرح مرض السكري و مضاعفاته للك من قبل الفريق الطبي؟ لإن

FIGURE 4: (D) The questionnaire form in Arabic 


\section{Cureus}

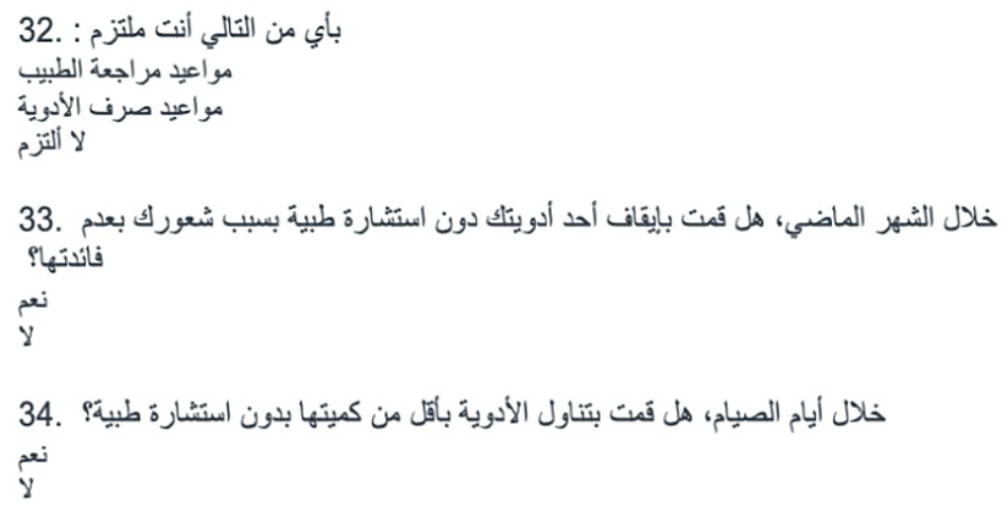

FIGURE 5: (E) The questionnaire form in Arabic

\section{Additional Information \\ Disclosures}

Human subjects: Consent was obtained or waived by all participants in this study. Ministry of Health's Institutional Review Board issued approval H-02-J-002. Ethical approval for conducting this study was obtained from the research committee of the Joint Program of Family Medicine, in Jeddah, and the Ministry of Health's Institutional Review Board (H-02-J-002), and the study was conducted in accordance with the principles of the Declaration of Helsinki. The confidentiality and anonymity of all participants were ensured. Verbal consent was obtained from each participant. Animal subjects: All authors have confirmed that this study did not involve animal subjects or tissue. Conflicts of interest: In compliance with the ICMJE uniform disclosure form, all authors declare the following: Payment/services info: All authors have declared that no financial support was received from any organization for the submitted work. Financial relationships: All authors have declared that they have no financial relationships at present or within the previous three years with any organizations that might have an interest in the submitted work. Other relationships: All authors have declared that there are no other relationships or activities that could appear to have influenced the submitted work.

\section{Acknowledgements}

The researchers would like to express their deepest gratitude and appreciation to the Joint Program of Family Medicine in Jeddah. Special thanks to Mikhael et al. who were generous and gracious enough to provide us with the IADMAS; to Doctor Sami Al Dobai and Doctor Sulafa Alqutub who offered valuable data and statistical analysis; and to all who contributed to fulfilling this study. Yara Khayyat, Reem Alshamrani, Doha Bintalib, Najwa Alzahrani contributed equally to the work and should be considered co-first authors. In addition, Doctor Sulafa Alqutub is acknowledged as a senior author.

\section{References}

1. World Health Organization. Global report on diabetes . (2016). Accessed: December 27, 2021: https://www.who.int/publications/i/item/9789241565257.

2. World Health Organization. Diabetes. (2021). Accessed: October 29, 2021: https://www.who.int/healthtopics/diabetes/\#tab=tab_1.

3. American Diabetes Association: Introduction: standards of medical care in diabetes-2022. Diabetes Care. 2022, 45:S1-S2. 10.2337/dc22-Sint

4. Guariguata L, Whiting DR, Hambleton I, Beagley J, Linnenkamp U, Shaw JE: Global estimates of diabetes prevalence for 2013 and projections for 2035. Diabetes Res Clin Pract. 2014, 103:137-149. 10.1016/j.diabres.2013.11.002

5. Aminde LN, Tindong M, Ngwasiri CA, Aminde JA, Njim T, Fondong AA, Takah NF: Adherence to antidiabetic medication and factors associated with non-adherence among patients with type-2 diabetes mellitus in two regional hospitals in Cameroon. BMC Endocr Disord. 2019, 19:35. 10.1186/s12902-019-03609

6. World Health Organization. Saudi Arabia diabetes country profile. (2016). Accessed: December 27, 2021: 
https://cdn.who.int/media/docs/default-source/country-profiles/diabetes/sau_en.pdf? sfvrsn=d3839de0_36\&download=true.

7. Demirtaş A, Akbayrak N: Development of an assessment scale for treatment compliance in type 2 Diabetes Mellitus in Turkish population: psychometric evaluation. Int J Nurs Sci. 2017, 4:244-251.

10.1016/j.ijnss.2017.06.002

8. Aloudah NM, Scott NW, Aljadhey HS, Araujo-Soares V, Alrubeaan KA, Watson MC: Medication adherence among patients with Type 2 diabetes: a mixed methods study. PLoS One. 2018, 13:e0207583. 10.1371/journal.pone.0207583

9. De Geest S, Sabaté E: Adherence to long-term therapies: evidence for action. Eur J Cardiovasc Nursing. 2003, 2:323. 10.1016/S1474-5151(03)00091-4

10. Khan AR, Al-Abdul Lateef ZN, Al Aithan MA, Bu-Khamseen MA, Al Ibrahim I, Khan SA: Factors contributing to non-compliance among diabetics attending primary health centers in the Al Hasa district of Saudi Arabia. J Family Community Med. 2012, 19:26-32. 10.4103/2230-8229.94008

11. Alqarni AM, Alrahbeni T, Al Qarni AA, Al Qarni HM: Adherence to diabetes medication among diabetic patients in the Bisha governorate of Saudi Arabia - a cross-sectional survey. Patient Prefer Adherence. 2019, 13:63-71. 10.2147/PPA.S176355

12. Khayyat SM, Mohamed MM, Khayyat SM, et al.: Association between medication adherence and quality of life of patients with diabetes and hypertension attending primary care clinics: a cross-sectional survey. Qual Life Res. 2019, 28:1053-1061. 10.1007/s11136-018-2060-8

13. Ahmed NO, Abugalambo S, Almethen GH: Adherence to oral hypoglycemic medication among patients with diabetes in Saudi Arabia. Int J Health Sci (Qassim). 2017, 11:45-49.

14. Brown MT, Bussell JK: Medication adherence: WHO cares?. Mayo Clin Proc. 2011, 86:304-314. 10.4065/mcp.2010.0575

15. Alhowaish AK: Economic costs of diabetes in Saudi Arabia . J Family Community Med. 2013, 20:1-7. 10.4103/2230-8229.108174

16. Lam WY, Fresco P: Medication adherence measures: an overview . Biomed Res Int. 2015, 2015:217047. 10.1155/2015/217047

17. Balkhi B, Alwhaibi M, Alqahtani N, et al.: Oral antidiabetic medication adherence and glycaemic control among patients with type 2 diabetes mellitus: a cross-sectional retrospective study in a tertiary hospital in Saudi Arabia. BMJ Open. 2019, 9:e029280. 10.1136/bmjopen-2019-029280

18. Lehane E, McCarthy G: Medication non-adherence--exploring the conceptual mire . Int J Nurs Pract. 2009, 15:25-31. 10.1111/j.1440-172X.2008.01722.x

19. Ganiyu AB, Mabuza LH, Malete NH, Govender I, Ogunbanjo GA: Non-adherence to diet and exercise recommendations amongst patients with type 2 diabetes mellitus attending Extension II Clinic in Botswana. Afr J Prim Health Care Fam Med. 2013, 5:457. 10.4102/phcfm.v5i1.457

20. Chakrabarti S: What's in a name? Compliance, adherence and concordance in chronic psychiatric disorders . World J Psychiatry. 2014, 4:30-36. 10.5498/wip.v4.i2.30

21. Walters-Salas T: The challenge of patient adherence. Bariatr Nurs Surg Patient Care. 2012, 7:186. 10.1089/bar.2012.9960

22. Salam MA, Siddiqui AF: Socio-demographic determinants of compliance among type 2 diabetic patients in Abha, Saudi Arabia. J Clin Diagn Res. 2013, 7:2810-2813. 10.7860/JCDR/2013/6986.3708

23. Alshehri KA, Altuwaylie TM, Alqhtani A, Albawab AA, Almalki AH: Type 2 diabetic patients adherence towards their medications. Cureus. 2020, 12:e6932. 10.7759/cureus.6932

24. Alhalaiqa F, Masa'Deh R, Batiha AM, Deane K: Validity of Arabic version of beliefs about medication questionnaire. Clin Nurs Res. 2015, 24:539-555. 10.1177/1054773814545383

25. Tiktin M, Celik S, Berard L: Understanding adherence to medications in type 2 diabetes care and clinical trials to overcome barriers: a narrative review. Curr Med Res Opin. 2016, 32:277-287.

10.1185/03007995.2015.1119677

26. About Jeddah city. (2021). Accessed: September 27, 2021: https://www.jeddah.gov.sa/english/jeddahcity/about/index.php.

27. Mikhael EM, Hussain SA, Shawky N, Hassali MA: Validity and reliability of anti-diabetic medication adherence scale among patients with diabetes in Baghdad, Iraq: a pilot study. BMJ Open Diabetes Res Care. 2019, 7:e000658. 10.1136/bmjdrc-2019-000658

28. Čulig J, Leppée M: From Morisky to Hill-Bone; self-reports scales for measuring adherence to medication . Coll Antropol. 2014, 38:55-62.

29. Sample size calculator. (2004). http://www.raosoft.com/samplesize.html.

30. SurveyMonkey. A global leader in survey software . (2021). https://www.surveymonkey.com/.

31. Horvat O, Popržen J, Tomas A, Paut Kusturica M, Tomić Z, Sabo A: Factors associated with non-adherence among type 2 diabetic patients in primary care setting in eastern Bosnia and Herzegovina. Prim Care Diabetes. 2018, 12:147-154. 10.1016/j.pcd.2017.10.002

32. Elsous A, Radwan M, Al-Sharif H, Abu Mustafa A: Medications adherence and associated factors among patients with type 2 diabetes mellitus in the Gaza Strip, Palestine. Front Endocrinol (Lausanne). 2017, 8:100. 10.3389/fendo.2017.00100

33. Raiff B, Jarvis BP, Dallery J: Text-message reminders plus incentives increase adherence to antidiabetic medication in adults with type 2 diabetes. J Appl Behav Anal. 2017, 49:947-953. 10.1002/jaba.337

34. Jaam M, Ibrahim MI, Kheir N, Awaisu A: Factors associated with medication adherence among patients with diabetes in the Middle East and North Africa region: a systematic mixed studies review. Diabetes Res Clin Pract. 2017, 129:1-15. 10.1016/j.diabres.2017.04.015

35. Abouammoh NA, Alshamrani MA: Knowledge about diabetes and glycemic control among diabetic patients in Saudi Arabia. J Diabetes Res. 2020, 2020:1239735. 10.1155/2020/1239735

36. Zowgar AM, Siddiqui MI, Alattas KM: Level of diabetes knowledge among adult patients with diabetes using diabetes knowledge test. Saudi Med J. 2018, 39:161-168. 10.15537/smj.2017.2.21343

37. Carballo M, Mohammad A, Maclean EC, Khatoon N, Waheedi M, Abraham S: Knowledge, attitudes, behaviours and practices towards diabetes mellitus in Kuwait. East Mediterr Health J. 2019, 24:1098-1102. 


\section{Cureus}

10.26719/2018.24.11.1098

38. Heissam K, Abuamer Z, El-Dahshan N: Patterns and obstacles to oral antidiabetic medications adherence among type 2 diabetics in Ismailia, Egypt: a cross section study. Pan Afr Med J. 2015, 20:177.

10.11604/pamj.2015.20.177.4025

39. Polonsky WH, Henry RR: Poor medication adherence in type 2 diabetes: recognizing the scope of the problem and its key contributors. Patient Prefer Adherence. 2016, 10:1299-1307. 10.2147/PPA.S106821

40. Barasa Masaba B, Mmusi-Phetoe RM: Determinants of non-adherence to treatment among patients with type 2 diabetes in Kenya: a systematic review. J Multidiscip Healthc. 2020, 13:2069-2076.

10.2147/JMDH.S270137 